\title{
Behaviour of Dietary Fibre Supplements During Bread Dough Development Evaluated Using Novel Farinograph Curve Analysis
}

\author{
Antoni Miś $^{1}$ - Agnieszka Nawrocka ${ }^{1} \cdot$ Dariusz Dziki $^{2}$
}

Received: 26 September 2016 / Accepted: 1 February 2017 /Published online: 10 February 2017

(C) The Author(s) 2017. This article is published with open access at Springerlink.com

\begin{abstract}
A regression model composed of two sigmoid functions with variable asymptotes was developed and used to analyse the dietary fibre supplement behaviour during bread dough mixing. Using eight commercial dietary fibres of different botanical origin and model wheat starch-gluten flour, farinograph curves for fibre-flour blends and for the flour only were performed. After smoothing of the curves with the regression model, difference farinograms as the fibre supplementation effects were determined. The results showed that the difference farinograms had two peaks, whose shape was strongly differentiated by the studied supplements. The presence of both peaks allowed distinguishing two kinds of the rheological activity of each fibre supplement: weakening and strengthening of the consistency of bread dough during its development. The carrot, oat, cranberry, and cacao fibres exhibited dominance of strengthening over weakening action. While chokeberry, carob, apple, and flax fibres were characterised by dominance of weakening over strengthening action. The analysis of both position and height of the peaks in the difference farinogram can be also helpful for determination of hydration kinetics of the fibres used for bread supplementation.
\end{abstract}

Electronic supplementary material The online version of this article (doi:10.1007/s11947-017-1881-8) contains supplementary material, which is available to authorized users.

Antoni Miś

a.mis@ipan.lublin.pl

1 Institute of Agrophysics, Polish Academy of Sciences, Doświadczalna 4, 20-290 Lublin, Poland

2 Department of Thermal Technology, University of Life Sciences, Doświadczalna 44, 20-280 Lublin, Poland
Keywords Two-peak farinogram $\cdot$ Fibre supplement $\cdot$ Model wheat dough $\cdot$ Fibre-gluten interaction $\cdot$ Dough development

\section{Introduction}

The farinograph method is still the leading standard tool (AACC 54-21 and ICC 115/1) in assessment of the rheological behaviour of wheat flours and technological and healthpromoting additives during the bread dough development and mixing processes. This has been demonstrated in the numerous current publications (Ahmad et al. 2016; Bigne et al. 2016; Krishnaiya et al. 2016; Nicolae et al. 2016; Quayson et al. 2016). The method consists in measurement of dough consistency $(C)$ in the function of the mixing time $(t)$. The $C$ values, although expressed in farinograph units (FU), are proportional to the magnitude of the torque of the stirrer arm, which balances the resistance of dough to shear stress (Migliori and Correra 2013). Changes in the consistency $C(t)$ presented in the graphic form are called a farinograph curve or a farinogram. Due to its shape, the typical farinograph curve is divided into two parts. The first part referred to as the dough development stage is characterised by an increase in the consistency $C(t)$, whereas the second part exhibits a decline in consistency $C(t)$ caused by overmixing and is called the dough softening stage ( Stojceska and Butler 2008).

The dough development stage is influenced by two basic processes: a hydration process, i.e. water absorption by the flour components; and a structure-formation process. The latter involves initiation of intermolecular bonds between gluten proteins, mainly disulphide, and gradual formation of a spatially continuous gluten network, which binds starch and other flour components (Letang et al. 1999; Maeda et al. 2015). Through these processes, the dough consistency increases. The slower the hydration of the flour components is, the 
longer the formation of the gluten network. Although the hydration and structure-formation processes at this stage of mixing are difficult to differentiate, appropriate hydration of flour is a determinant of the normal course of the structureformation process. However, they have opposite effects on the dough consistency. Increasing dough hydration induced a decrease in the dough consistency, whereas an increasing number of intermolecular bonds forming the gluten network contribute to enhanced dough consistency (Lefebvre and Mahmoudi 2007). The dough development stage ends at the time when continued mixing leads to noticeable weakening of dough consistency, i.e. the softening stage begins. The changes in dough consistency described above are visualised by a single-peak farinogram and are typical of homogeneous wheat flour types containing no additives.

Greater interpretation difficulties are posed by farinograms with a more complex course and multiple peaks. This type of farinograms are often yielded when dough is produced from a blend of several wheat flour types differing in both physical parameters, e.g. water diffusivity and flour particle size (Migliori and Correra 2013), and chemical composition, in particular the content of HMW glutenins (Hammed et al. 2015). Some of health-promoting additives can also dramatically alter the rheological behaviour of bread dough by influencing hydration and conformational changes in gluten proteins. This type of additives are represented by dietary fibres, which are characterised by increased water absorption (Chareonthaikij et al. 2016; Jacobs et al. 2015; Bchiretal.2014) and the presence of reactive antioxidants (Han and Koh 2011; Noort et al. 2010; Rosa et al. 2013). The greater degree of water absorption exhibited by fibre, in comparison with gluten proteins, can induce a dehydration phenomenon during the mixing process. It involves migration of water from flour components, primarily gluten and starch, to fibre particles, leading to partial dehydration (Bock and Damodaran 2013; Pourfarzad et al. 2015). A poorly hydrated gluten network becomes less elastic and more resistant to mixing. This dehydration-induced increase in dough consistency can be an explanation of the appearance of the second peak on the farinograph curve (Huang et al. 2016; Miś et al. 2012; Salinas et al. 2015; Teng et al. 2015). The shape of the second peak can also be influenced by chemical interactions between fibre and gluten proteins. Results of our previous studies performed with Raman spectroscopy (Nawrocka et al. 2015; Nawrocka et al. 2016a; Nawrocka et al. 2016b) indicate that fibre substantially modifies the conformational structure of proteins during dough development, i.e. it increases the proportion of hydrogen-bonded $\beta$-sheets due to aggregation or abnormal folding. The structural modifications have a simultaneous impact on the viscoelasticity of the gluten network, making it stiffer. Therefore, a more detailed analysis of the shape of the farinograph curve, in particular the position and height of the second peak, may be valuable for rheological characterisation of fibre supplements used in bread production.
The aim of the study was to develop a nonlinear regression model that can be used for description of the shape of a two-peak farinogram and a method for determination of a difference farinogram illustrating the rheological effect induced by the fibre supplement during bread dough mixing. Until recently, the results of farinograph measurements have been presented as a total effect of the interactions between all dough components rather than in the form of difference farinograms showing the impact of the individual dough ingredients. The method of analysis of difference farinograms developed in this study may greatly expand the knowledge of the hydration and rheological properties of fibre supplements and fibre-gluten interactions, which will contribute to development of solutions improving the technology of fibre-supplemented bread production.

\section{Materials and Methods}

\section{Materials}

The investigations consisted in assessment of the rheological properties of eight commercial fibre supplements. The apple (APL), cacao (CAC), chokeberry (CHB), cranberry (CRB), carrot (CRR), oat (OAT), and flax (FLX) fibres were provided by Microstructure (Warsaw, Poland), and the carob (CAR) fibre was produced by Carob General Application, (Valencia, Spain). The content and fraction composition of the dietary fibre in the analysed supplements specified by the manufacturers were reported in our previous publication (Nawrocka et al. 2015).

Two components, i.e. wheat starch (Cargill, Holland) and wheat gluten (Sigma-Aldrich, Poland), were used for preparation of the model flour. The use of model flour for analysis of fibre-gluten interactions is advisable, since this eliminates potential interference from native wheat fibre, thereby contributing to higher objectivity of the rheological characterisation of bread fibre supplements.

\section{Water Retention Capacity}

The fibre supplements were analysed for their water retention capacity with the procedure developed by Raghavendra et al. (2004). A 1-g portion of the fibre supplements was prepared and $30 \mathrm{~mL}$ of distilled water were added. The sample was shaken for $18 \mathrm{~h}$ at a temperature of $30^{\circ} \mathrm{C}$ and next centrifuged $(3000 \times g)$ for $20 \mathrm{~min}$. The supernatant was removed and the centrifuged fibre sample was dried for $12 \mathrm{~h}$ at $105^{\circ} \mathrm{C}$. Water retention capacity (WRC) was calculated using the formula:

$\mathrm{WRC}=\mathrm{RHW} / \mathrm{RDW}-1$

where RHW is residue hydrated weight after centrifugation and RDW is the residue dry weight. 


\section{Particle Size Distribution}

The particle size distribution was measured with the laser diffraction method using a Mastersizer 2000 laser diffractometer (Malvern, UK) with a 0.02-2000 $\mu$ m measuring range. The measurements were performed in water, adopting a refractive index of 1.52 and an absorption coefficient of 0.1 for the analysed particles (Bieganowski et al. 2012). The determinations were carried out using a Hydro G dispersion unit at a pump velocity of $1750 \mathrm{rpm}$ and a stirrer speed of $700 \mathrm{rpm}$ (Bieganowski et al. 2013). The particle size measurement results are presented as a volume-equivalent sphere diameter $-\mathrm{D}[4,3]$.

\section{Proposed Method for Determining a Difference Farinogram}

The essence of the developed method (Miś and Nawrocka 2015 ) is division, at any time of mixing $t$, of the consistency $C(t)$ of dough made of wheat flour (M) and the fibre supplement $(\mathrm{F})$ into two components $C_{\mathrm{M}}(t)$ and $C_{\mathrm{F}}(t)$ in accordance with the formula:

$C(t)=C_{\mathrm{M}}(t) \cdot\left(1-\varphi_{\mathrm{F}}\right)+C_{\mathrm{F}}(t) \cdot \varphi_{\mathrm{F}}$,

where $C_{\mathrm{M}}(t)$ is the consistency of dough made of wheat flour only $\left(1-\varphi_{\mathrm{F}}=1\right), C_{\mathrm{F}}(t)$ is a difference farinogram illustrating changes in the dough consistency induced by the fibre supplement, assuming that $\varphi_{\mathrm{F}}=1$ and $\varphi_{\mathrm{F}}$ is the weight proportion of the fibre supplement in the wheat flour and fibre blend. The impact of the supplement on dough consistency can be both physical, e.g. a decrease in the gluten hydration degree caused by competition for water, and chemical, e.g. formation of protein-fibre complexes and/or modification of the conformational structure of gluten proteins. The proposed method takes into account the phenomenon of gluten and dough diluting by the fibre supplement. Its impact on the dough consistency $C_{\mathrm{M}}(t)$ is represented with expression $\left(1-\varphi_{\mathrm{F}}\right)$ in formula (2). In the investigations of the fibre hydration phenomenon and its impact on the course of $C_{\mathrm{F}}(t)$, both $C(t)$ and $C_{\mathrm{M}}(t)$ measurements should be done at the same dough hydration level. This is indicated by the investigations conducted by Bock and Damodaran (2013) on model bran-gluten dough. They demonstrated a significant effect of the water content in the dough on changes induced by wheat bran in the secondary structure of gluten. Hence, measurements of $C(t)$ and $C_{\mathrm{M}}(t)$ carried out at a constant dough consistency (500 FU) prevent objective comparison of the rheological properties of fibres based on difference farinograms $C_{\mathrm{F}}(t)$, since their course also results from differences in dough hydration.

In accordance with the proposed method, the first step consisted in determination of changes in the consistency $C(t)$ of dough that was a mixture of the model flour and the fibre supplement. To this end, starch and gluten in a weight ratio of $80: 15$ were placed in a farinograph mixer chamber (Brabender, Germany), and next the fibre supplement was added in an amount corresponding to $\varphi_{\mathrm{F}}=0.18$ at a constant baseline moisture of $14 \%$ for starch, gluten, and the fibre supplement. In order to homogenise the blend, the components were mixed for 1 min. Next, with continuous mixing, a specified volume of water was poured into the $50 \mathrm{-g}$ volume mixer chamber (Farinograph-E, Brabender, Germany) to achieve the water absorption equal to $70 \mathrm{~g}$ of water $/ 100 \mathrm{~g}$ of the model flour-fibre supplement blend with $14 \%$ moisture content. Such a quantity of water ensured consistency $C(t)$ with a maximum value not exceeding $500 \mathrm{FU}$, i.e. the optimum level for bread dough development. The dough mixing test was initiated upon water addition, and the consistency $C(t)$ values were recorded at $30 \mathrm{~min}^{-1}$ intervals. The mixing time was $20 \mathrm{~min}$.

In the second step, changes in the consistency $C_{\mathrm{M}}(t)$ of the dough prepared from the model flour only were determined in the same way and in the same conditions.

In the third step, the results of $C(t)$ and $C_{\mathrm{M}}(t)$ were subjected to nonlinear regression analysis (Statsistica v.12, StatSoft, Tulsa, USA) to fit the developed regression model in the following form:

$$
\begin{aligned}
C(t) \operatorname{or} C_{\mathrm{M}}(t)= & a_{1} \cdot \exp \left(b_{1} \cdot\left(c_{1}-t\right)\right) /\left(1+\exp \left(d_{1} \cdot\left(c_{1}-t\right)\right)\right) \\
& +a_{2} \cdot \exp \left(b_{2} \cdot\left(c_{2}-t\right)\right) /\left(1+\exp \left(d_{2} \cdot\left(c_{2}-t\right)\right)\right),
\end{aligned}
$$

where $a_{1}, b_{1}, c_{1} d_{1}, a_{2}, b_{2}, c_{2}$, and $d_{2}$ are the determined parameters of the model. The model is a sum of two sigmoid functions with variable asymptotes; hence, the two peaks of the farinograph curve can be ideally represented. Successfully, this model can also be used to describe the typical farinograph curves with the single peak. Figure $1 \mathrm{a}, \mathrm{b}$ presents two examples of farinograms $C(t)$ and $C_{\mathrm{M}}(t)$ with the values of the regression model parameters and the degree of fit $\left(R^{2}\right)$. The coefficient of determination $R^{2}$ ranged from 0.96 to 0.99 , which confirms the very good fit of the model to the experimental data.

Based on the fitted $C(t)$ and $C_{\mathrm{M}}(t)$ models, the fourth, and last, step of the procedure consisted in determination of the changes in consistency $C_{\mathrm{F}}(t)$ induced by the fibre effect, using a formula:

$C_{\mathrm{F}}(t)=\left[C(t)-C_{\mathrm{M}}(t) \cdot\left(1-\varphi_{\mathrm{F}}\right)\right] / \varphi_{\mathrm{F}}$

which is a transformation of formula (2). Regardless of the fibre type, each difference curve $C_{\mathrm{F}}(t)$ (Fig. 2) had two characteristic peaks differing in the span, height, and slope of the arms. Figure 3 shows graphic representation of the adopted mode of analysis of the two-peak curve $C_{\mathrm{F}}(t)$ with characteristic moments during the dough 
Fig. 1 Changes in dough consistency during mixing and fitting of farinograph measurements to developed regression model. a Model flour with fibre supplement (CRB). b Model flour only a

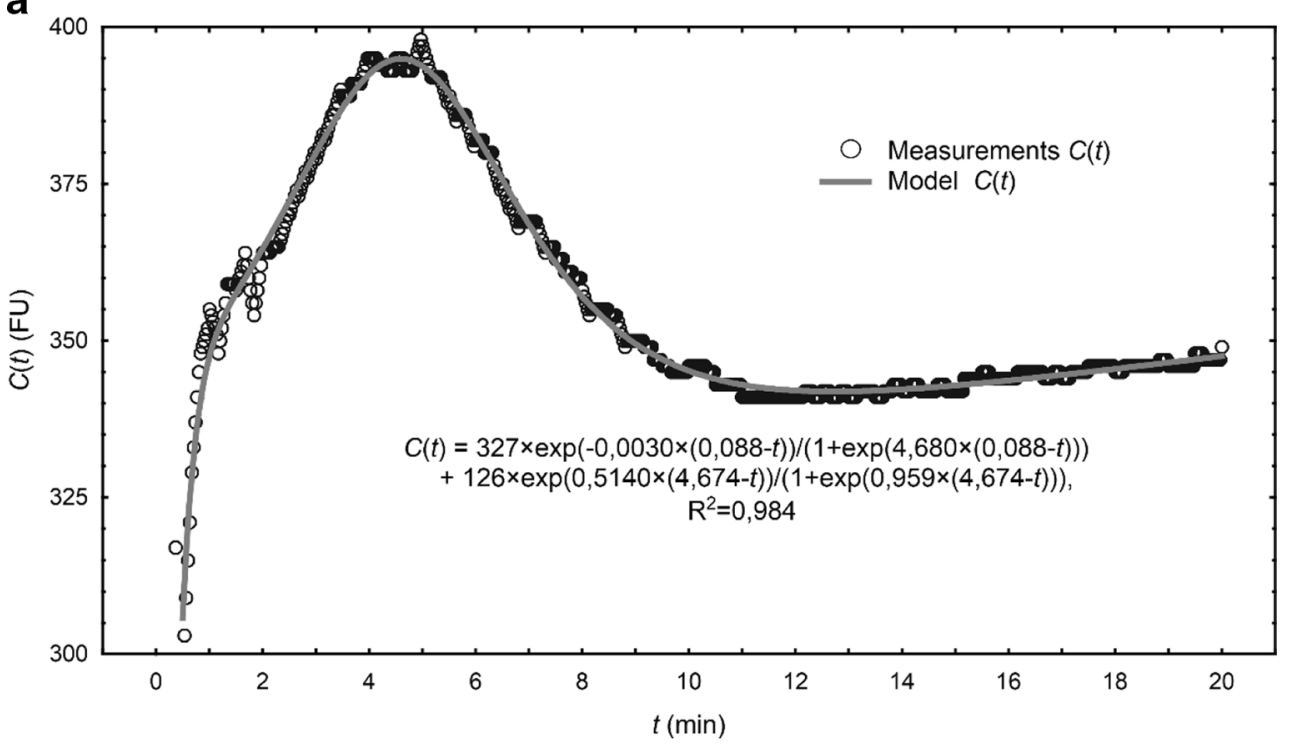

b

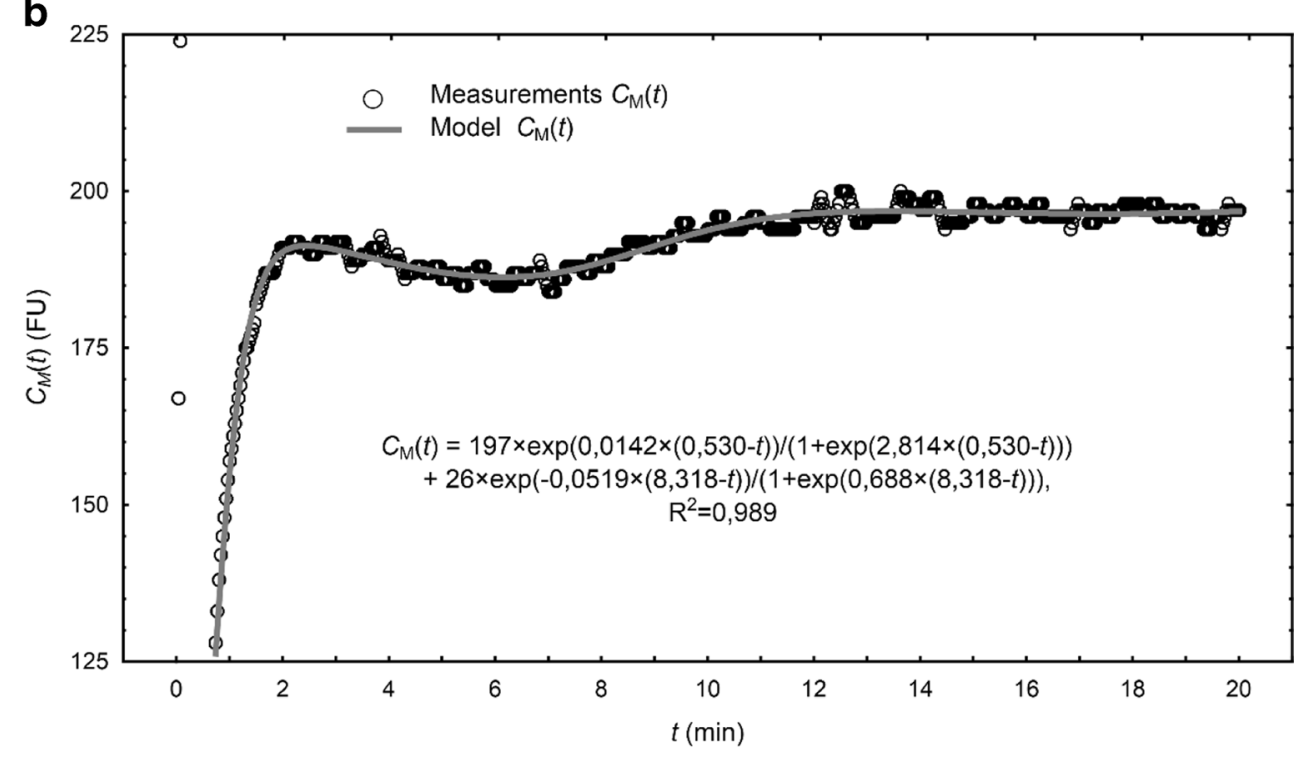

mixing stage, based on which the following indices of the rheological properties of the fibre supplement were determined:

- peak $\mathrm{p}_{1}$ and $\mathrm{p}_{2}$ height, as $C_{\mathrm{F}}\left(t_{\mathrm{p} 1}\right)$ and $C_{\mathrm{F}}\left(t_{\mathrm{p} 2}\right)$ values;

- $\quad$ span $W_{\mathrm{p} 1}$ and $W_{\mathrm{p} 2}$ of peaks $\mathrm{p}_{1}$ and $\mathrm{p}_{2}$, in accordance with the formulas:

$W_{\mathrm{p} 1}=t_{\mathrm{CFMIN}}-t_{0}$,

$W_{\mathrm{p} 2}=t_{\mathrm{RMINp} 2}-t_{\mathrm{CFMIN}}$,

- $\quad$ ratio of the spans of peaks $\mathrm{p}_{1}$ and $\mathrm{p}_{2}$, as a $W_{\mathrm{p} 2} / W_{\mathrm{p} 1}$ value;

- $\quad$ slope of the arms of peaks $\mathrm{p}_{1}$ and $\mathrm{p}_{2}$, as $R_{\mathrm{MAXp} 1}, R_{\mathrm{MINp} 1}$, $R_{\mathrm{MAXp} 2}$, and $R_{\mathrm{MINp} 2}$ values;
- effect of weakening the dough consistency $S$, in accordance with the formula:

$$
S=1-C_{\mathrm{F}}\left(t_{\mathrm{CFMIN}}\right) / C_{\mathrm{F}}\left(t_{\mathrm{p} 1}\right),
$$

- effect of strengthening the dough consistency $H$, in accordance with the formula:

$H=\left[C_{\mathrm{F}}\left(t_{\mathrm{p} 2}\right)-C_{\mathrm{F}}\left(t_{\text {CFMIN }}\right)\right] / C_{\mathrm{F}}\left(t_{\mathrm{p} 1}\right)$,

- time of rheological activity $t_{\mathrm{A}}$, in accordance with the formula:

$t_{\mathrm{A}}=t_{\mathrm{p} 2}-t_{\mathrm{p} 1}$, 
Fig. 2 Graphical comparison of rheological activity of studied fibre supplements during dough mixing. a A set of fibres for which $C_{\mathrm{F}}\left(t_{\mathrm{p} 1}\right)<C_{\mathrm{F}}\left(t_{\mathrm{p} 2}\right)$. b A set of fibres for which $C_{\mathrm{F}}\left(t_{\mathrm{p} 1}\right)>C_{\mathrm{F}}\left(t_{\mathrm{p} 2}\right)$

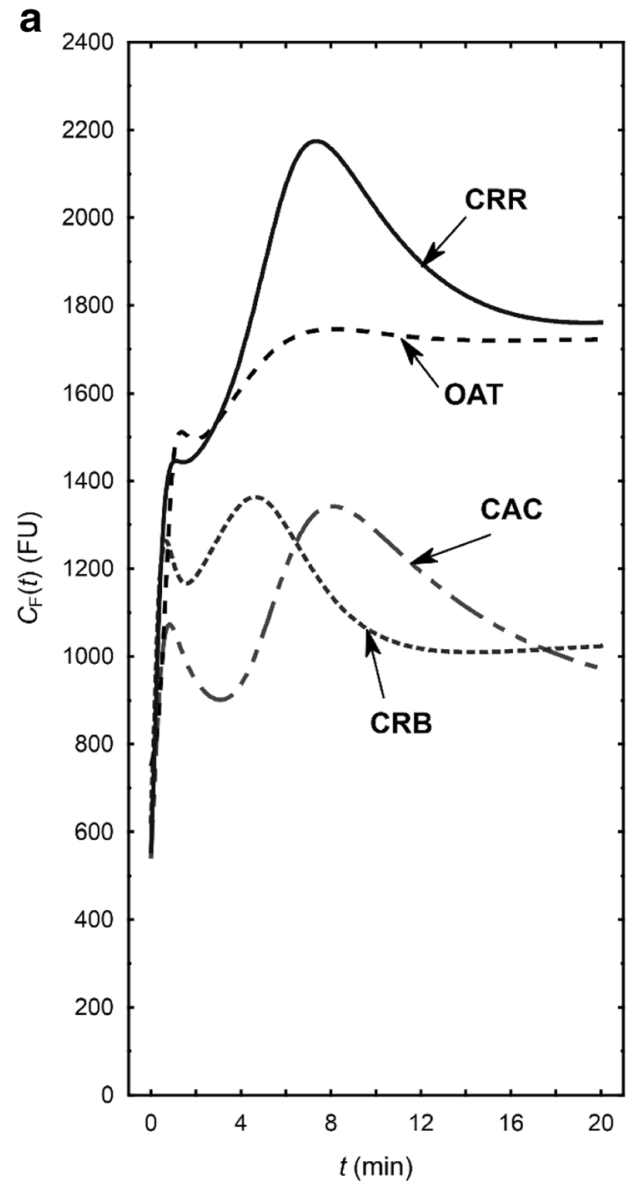

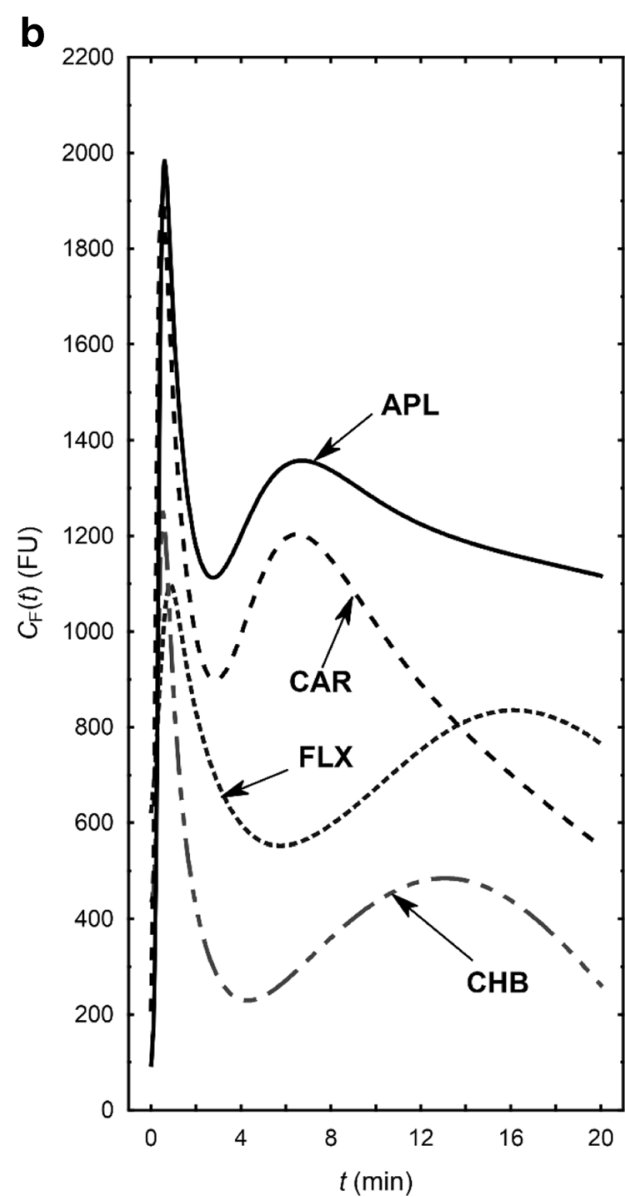

- rheological activity $A$, in accordance with the formula:

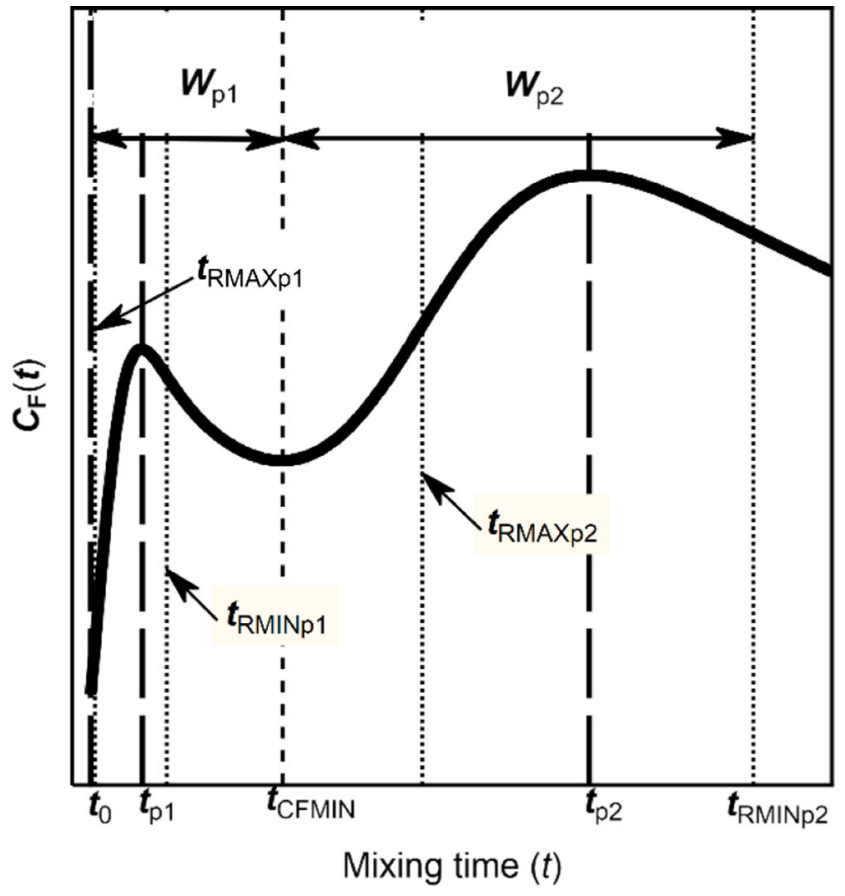

Fig. 3 Characteristic moments in run of $C_{\mathrm{F}}(t)$ curve used to analyse rheological activity of fibre supplements
$A=C_{\mathrm{F}}\left(t_{\mathrm{p} 1}\right) \cdot(S+H) / t_{\mathrm{A}}$,

where $t_{\mathrm{p} 1}$ and $t_{\mathrm{p} 2}$ are moments of the mixing, for which $C_{\mathrm{F}}\left(t=t_{\mathrm{p} 1}\right)$ and $C_{\mathrm{F}}\left(t=t_{\mathrm{p} 2}\right)$ reach local maxima; $t_{\mathrm{CFMIN}}$ is the mixing time between $t_{\mathrm{p} 1}$ and $t_{\mathrm{p} 2}$, for which $C_{\mathrm{F}}\left(t=t_{\mathrm{CFMIN}}\right)$ reaches a minimum; $t_{0}$ is the time of the beginning of mixing; $t_{\mathrm{RMINp} 2}$ is the moment during the mixing time $t_{\mathrm{p} 2}>t \leq t_{\mathrm{F}}$ when the rate of consistency changes $d C_{\mathrm{F}}\left(t=t_{\mathrm{RMINp} 2}\right) / d t$ has the lowest value; $t_{\mathrm{F}}$ is the time of the end of mixing; $R_{\mathrm{MAXp} 1}$ and $R_{\mathrm{MINp} 1}$ are the maximum and minimum rates of consistency change, respectively, at time $t_{0}>t<t_{\mathrm{CFMIN}}$; and $R_{\mathrm{MAXp} 2}$ and $R_{\mathrm{MINp} 2}$ are the maximum and minimum rates of consistency change, respectively, at time $t_{\mathrm{CFMIN}}>t \leq t_{\mathrm{F}}$.

\section{Statistical Analyses}

Analyses of variance and correlation of the measured indices were conducted using the software Statistica v.12, PL (StatSoft Inc., Tulsa, USA). Measurements of water retention capacity, particle size distribution, and farinograph curves $C(t)$ 
and $C_{\mathrm{M}}(t)$ as well as determinations of the difference farinograph curves $C_{\mathrm{F}}(t)$ and the proposed rheological indices were performed in three replications. The significance of the differences in the studied effects between the fibre supplements was evaluated using one-way analysis of variance (ANOVA) followed by Tukey's test $(p<0.05)$. In all tables, the results are presented as means \pm standard deviations of three replications.

\section{Results and Discussion}

\section{Hydration and Particle Size Characteristics of Fibre Supplements}

The hydration properties of fibre depend primarily on the botanical (species and type of plant tissue) and environmental origin of the raw material used for fibre extraction. Similarly, the fibre extraction and grinding technology can substantially modify the hydration properties of fibre supplements (Ma and Mu 2016; Massiot and Renard 1997; Mert et al. 2014).

The fibres analysed in this study differed substantially in their hydration capacity and particle size distribution (Table 1); however, these parameters were not correlated (Table S1 in the Supplementary Material). Using different sizes of wheat bran particles obtained by grinding, Auffret et al. (1994), Jacobs et al. (2015), and Zhang and Moore (1999) observed a decline in water retention capacity with the decreasing particle diameter. Otherwise, Roth et al. (2016) using dried distiller's grains as the fibre supplement of particle size fractions, $<750,<500$, and $<250 \mu \mathrm{m}$, showed no significant influence of the fractions on water absorption that was determined using dough LAB kneader. In our investigations of different botanical origin fibres, the dominant effect on the differences in the WRC parameter, besides the particle size, was probably exerted by the chemical composition of the fibre (Nawrocka et al. 2015). The major role in the differentiation of the hydration properties is ascribed to hydroxyl groups, which increase the water retention capacity of fibre (Rosell et al. 2006).

The WRC values (Table 1) ranged from $2.9 \mathrm{~g} \mathrm{~g}^{-1}$ (CHB) to $14.7 \mathrm{~g} \mathrm{~g}^{-1}$ (FLX) and were several times higher than the WRC values for starch $\left(1.5 \mathrm{~g} \mathrm{~g}^{-1}\right)$ and wheat gluten $\left(2.9 \mathrm{~g} \mathrm{~g}^{-1}\right)$, i.e. the components of the model flour. The finest particle size was noted for the carob and chokeberry fibres, with the $\mathrm{D}[4,3]$ values of 48 and $58 \mu \mathrm{m}$, respectively. In turn, the greatest particle size was exhibited by the oat $(354 \mu \mathrm{m})$ and cranberry $(211 \mu \mathrm{m})$ fibres, which contained 80 and $86 \%$ of particles $>50 \mu \mathrm{m}$, respectively.

\section{Rheological Characteristics of Fibre Supplements}

In contrast to the standard farinograph method, the rheological behaviour of the analysed fibres was evaluated based on the course of difference farinograms $C_{\mathrm{F}}(t)$. They show the rheological effect of the fibre only $\left(\varphi_{\mathrm{F}}=1\right)$, as the effect of the other dough components, in particular gluten and starch, was eliminated by the method applied (section Proposed Method for Determining a Difference Farinogram). To emphasise the differences in the rheological activity of the eight fibres analysed, Fig. 2a presents fibres, whose peaks $\mathrm{p}_{1}$ of curves $C_{\mathrm{F}}(t)$ were lower than peaks $\mathrm{p}_{2}$. In turn, Fig. 2b shows fibres, which exerted an opposite effect on the height of these peaks $\left(C_{\mathrm{F}}\left(t_{\mathrm{p} 1}\right)>C_{\mathrm{F}}\left(t_{\mathrm{p} 2}\right)\right)$.

The fibre supplements significantly differentiated the course of the curves $C_{\mathrm{F}}(t)$. The differences between the fibres involved the position of the $\mathrm{p}_{1}$ and $\mathrm{p}_{2}$ peaks on the mixing time axis as well as their shape and height.

Among the indices determined (Table 2), the position $\left(t_{\mathrm{p} 1}\right)$ and slope of the arms $\left(R_{\mathrm{MAXp} 1}\right.$ and $\left.R_{\mathrm{MINp} 1}\right)$ of the first peak were the least differentiated by the analysed fibres. The $\mathrm{p}_{1}$ peak typically appeared after ca. 0.5 -min mixing, with the exception of the carrot and oat fibres, which were the largest particles and, therefore, required a considerably longer mixing time, i.e. 1.0 and $1.3 \mathrm{~min}$, respectively. This is confirmed by the study carried out by Majzoobi et al. (2014), who demonstrated the impact of the coarser granulation of wheat bran on the prolongation of the time of bread dough development. In turn, fibres with several-fold smaller particle diameters $(\mathrm{D}[4,3])$, in particular carob and apple fibres, exhibited the greatest arm slopes $\left(R_{\mathrm{MAXp} 1}, R_{\mathrm{MINp} 1}\right)$ and the highest peaks $\mathrm{p}_{1}\left(C_{\mathrm{Fp} 1}\right)$ up to ca. $1900 \mathrm{FU}$. Such high rheological activity of these fibres may have been largely dependent on their rapid hydration rate, which increases together with a decreasing diameter of hydrated particles (Migliori and Correra 2013). In turn, fibres with the largest particles, i.e. oat and carrot fibres, induced formation of medium-height peaks (1400$1500 \mathrm{FU})$. Despite the significant differences in $\mathrm{D}[4,3]$, the other four fibres had $p_{1}$ peaks with a similar height ranging from ca. 1150 to ca. $1250 \mathrm{FU}$. This is also evidenced by lack of correlations (Table $\mathrm{S} 1$ ) between the particle size parameters and the $R_{\mathrm{MAXp1}}$ and $C_{\mathrm{Fp} 1}$. Probably, the fibre hydration kinetics may have been influenced by other physical and chemical parameters, e.g. the specific surface and texture, in particular porosity (Jacobs et al. 2015), and the chemical composition (Nawrocka et al. 2015) of the fibre supplements.

The correlations presented in Table S1 showed that the inclusion of a fibre fraction with finer particles $(0.02-2 \mu \mathrm{m})$ into the bread dough increased the rate $\left(R_{\mathrm{MINp} 1}\right)$ and degree of its consistency weakening $(S)$, whereas the fraction with larger particles $(50-2000 \mu \mathrm{m})$ extended the peak $\mathrm{p}_{1}$ formation time $\left(t_{\mathrm{p} 1}\right)$ and slowed down the weakening process. This indicates that the number of fibre particles per unit of supplement weight, which is greater in the finer fractions, may be an important criterion in the assessment of the weakening effect of fibre. This may be related to the fact that a greater number of fibre particles induces greater disruption of the gluten network continuity and thus weakens its stability. This is also 
Table 1 Water retention capacity $(W R C)$ and volume weighted mean diameter $\mathrm{D}[4,3]$ and size distribution of particles of dietary fibre supplements;

means \pm standard deviation

\begin{tabular}{|c|c|c|c|c|c|c|c|c|}
\hline \multirow[t]{2}{*}{ Indices } & \multicolumn{8}{|c|}{ Dietary fibre supplements } \\
\hline & APL & CAC & $\mathrm{CHB}$ & $\mathrm{CRB}$ & CRR & FLX & OAT & CAR \\
\hline \multirow[t]{2}{*}{ WRC $\left(g \cdot g^{-1}\right)$} & $6.4^{\mathrm{d}}$ & $6.5^{\mathrm{d}}$ & $2.9^{\mathrm{a}}$ & $5.3^{\mathrm{c}}$ & $9.2^{\mathrm{e}}$ & $14.7^{\mathrm{f}}$ & $3.9^{\mathrm{b}}$ & $3.5^{\mathrm{ab}}$ \\
\hline & \pm 0.1 & \pm 0.1 & \pm 0.2 & \pm 0.1 & \pm 0.3 & \pm 0.3 & \pm 0.2 & \pm 0.2 \\
\hline \multirow[t]{2}{*}{$D[4,3](\mu \mathrm{m})$} & $84.0^{\mathrm{c}}$ & $70.9^{\mathrm{bc}}$ & $58.3^{\mathrm{ab}}$ & $211.1^{\mathrm{e}}$ & $138.3^{\mathrm{d}}$ & $143.6^{\mathrm{d}}$ & $353.5^{\mathrm{f}}$ & $48.2^{\mathrm{a}}$ \\
\hline & \pm 1.3 & \pm 0.9 & \pm 2.1 & \pm 3.8 & \pm 1.4 & \pm 1.6 & \pm 5.7 & \pm 0.1 \\
\hline \multicolumn{9}{|c|}{ Share of size fractions (\%) } \\
\hline \multirow[t]{2}{*}{$0.02-2 \mu \mathrm{m}$} & $1.39^{\mathrm{c}}$ & $1.89^{\mathrm{d}}$ & $3.37^{\mathrm{e}}$ & $0.91^{\mathrm{b}}$ & $0.33^{\mathrm{a}}$ & $1.88^{\mathrm{d}}$ & $1.18^{\mathrm{c}}$ & $3.17^{\mathrm{e}}$ \\
\hline & \pm 0.05 & \pm 0.05 & \pm 0.08 & \pm 0.03 & \pm 0.03 & \pm 0.08 & \pm 0.05 & \pm 0.03 \\
\hline \multirow[t]{2}{*}{$2-50 \mu \mathrm{m}$} & $44.7^{\mathrm{e}}$ & $47.7^{\mathrm{f}}$ & $57.1^{\mathrm{g}}$ & $18.7^{\mathrm{b}}$ & $34.6^{\mathrm{d}}$ & $30.9^{\mathrm{c}}$ & $12.8^{\mathrm{a}}$ & $58.3^{\mathrm{g}}$ \\
\hline & \pm 0.4 & \pm 0.3 & \pm 0.2 & \pm 0.2 & \pm 0.2 & \pm 0.6 & \pm 0.1 & \pm 0.1 \\
\hline \multirow[t]{2}{*}{$50-2000 \mu \mathrm{m}$} & $53.9^{\mathrm{c}}$ & $50.4^{\mathrm{b}}$ & $39.6^{\mathrm{a}}$ & $80.4^{\mathrm{f}}$ & $65.1^{\mathrm{d}}$ & $67.2^{\mathrm{e}}$ & $86.0^{\mathrm{g}}$ & $38.6^{\mathrm{a}}$ \\
\hline & \pm 0.5 & \pm 0.4 & \pm 0.3 & \pm 0.2 & \pm 0.3 & \pm 0.7 & \pm 0.1 & \pm 0.1 \\
\hline
\end{tabular}

Values in the same row followed by different superscript letters are significantly different from each other $(p<0.05)$ confirmed in the investigations conducted by Noort et al. (2010), who reported that gluten proteins in the presence of wheat bran, which has finer particles, were characterised by a poor capability of aggregation and formation of a coherent network, resulting in lower amounts of washed-out gluten.

The phenomenon of dough softening in the case of the carrot and oat fibres was virtually undetectable, as the $S$ value was merely 0.01 . This may indicate that the exceptionally low rate of hydration of these fibres, which is indicated by the twofold longer times of formation of the first peak $\left(t_{\mathrm{p} 1}\right)$, is technologically most beneficial, since it caused the slightest disturbances in the rheological stability of the gluten network during the initial dough development $\left(W_{\mathrm{p} 1}\right)$. In contrast, the chokeberry, carob, and flax fibres considerably weakened the dough consistency and, consequently, the $S$ index was over 0.8 .

The location of the difference curve depression $\left(t_{\mathrm{CFMIN}}\right)$ is concurrently the measure of the span of the first peak $\left(W_{\mathrm{p} 1}\right)$ (Fig. 3). The flax fibre, which has the highest $W R C$ value, was characterised by the broadest peak $\mathrm{p}_{1}$ (almost 6-min span). In turn, extremely narrow peaks $\mathrm{p}_{1}$ were observed for the carrot and cranberry fibres, and their span values were 1.4 and $1.6 \mathrm{~min}$, respectively. The spans of the $\mathrm{p}_{2}$ peaks $\left(W_{\mathrm{p} 2}\right)$ were substantially, usually twofold higher than those of the $p_{1}$ peaks. In the case of the carrot fibre, whose peak $p_{1}$ was the narrowest, the $W_{\mathrm{p} 2} / W_{\mathrm{p} 1}$ ratio reached 5.8. However, in terms of absolute values, the broadest $\mathrm{p}_{2}$ peaks were noted for the chokeberry (15.7 $\mathrm{min})$ and $(14.2 \mathrm{~min})$ flax fibres. The consequence of the broader span of the $\mathrm{p}_{2}$ peaks was the flatter slope of their arms. Compared with $R_{\mathrm{MAXp} 1}$ and $R_{\mathrm{MINp} 1}$, the $R_{\mathrm{MAXp} 2}$ and $R_{\mathrm{MINp} 2}$ values were substantially lower, i.e. on average 23- and 9-fold, respectively. This may indicate that the kinetics of processes responsible for the formation of the second peak is very slow, which are likely to be associated with migration of bound water from the flour components to the fibre.
The height of peaks $\mathrm{p}_{2}\left(C_{\mathrm{Fp} 2}\right)$ was highly differentiated between the analysed fibres, which allowed distinguishing six homogeneous groups (Table 2). Their height ranged from $505 \mathrm{FU}$ (CHB) to $2178 \mathrm{FU}$ (CRR), which was over twofold wider than the range of values for peaks $\mathrm{p}_{1}$. Furthermore, the heights of peaks $p_{2}$ and $p_{1}$ were not correlated (Table $\mathrm{S} 1$ ). This may imply different processes of formation of these two peaks. Undoubtedly, peak $\mathrm{p}_{2}$ reflects the phenomenon of consistency strengthening at the end of the dough development stage. Four fibres, i.e. APL, CRB, CAR, and OAT, exerted a very poor strengthening effect; their $H$ index ranged from 0.13 to 0.17 . The strongest dough consistency strengthening effect was noted for the carrot $(H=0.54)$ and cacao $(H=0.38)$ fibres.

At shaping both $\mathrm{p}_{1}$ and $\mathrm{p}_{2}$ peaks, the course of the hydration process of the fibre supplement plays surly a dominating role. Initially $\left(W_{\mathrm{p} 1}\right)$, fibre particles absorb the free water, which takes a place between by the dough components. When free water is used $\left(W_{\mathrm{p} 2}\right)$, further hydration of the fibre supplement is achieved through migration of bound water from the proteins of the dough gluten network and starch grains to the fibre, which exhibits higher water absorption strength. A rheological consequence of the progressive gluten and starch dehydration is the slow increase in the dough consistency $\left(R_{\mathrm{MAXp} 2}\right)$, and the total range of the increase is indicated by the $H$ index (Table 2). Along the increase in the quantity of water (plasticiser) lost by gluten and starch, the gluten network becomes firmer and the starch granules become stiffer, which leads to greater resistance of the dough to shearing. According to this interpretation, the $H$ index could be an indicative measure of the gluten dehydration degree or, alternatively, a measure of the water absorption strength of fibre, which forces this 
Table 2 Rheological characteristics of dietary fibre supplements; $t_{0}=0 \mathrm{~min}$, means \pm standard deviation

\begin{tabular}{|c|c|c|c|c|c|c|c|c|}
\hline \multirow[t]{2}{*}{ Rheological indices } & \multicolumn{8}{|c|}{ Dietary fibre supplements } \\
\hline & APL & $\mathrm{CAC}$ & $\mathrm{CHB}$ & CRB & CRR & FLX & OAT & CAR \\
\hline \multirow[t]{2}{*}{$t_{\mathrm{p} 1}(\min )$} & $0.50^{\mathrm{a}}$ & $0.67^{\mathrm{a}}$ & $0.50^{\mathrm{a}^{*}}$ & $0.68^{\mathrm{a}}$ & $1.01^{\mathrm{b}}$ & $0.78^{\mathrm{ab}}$ & $1.32^{\mathrm{c}}$ & $0.53^{\mathrm{a}}$ \\
\hline & \pm 0.15 & \pm 0.17 & \pm 0.03 & \pm 0.05 & \pm 0.13 & \pm 0.15 & \pm 0.05 & \pm 0.03 \\
\hline \multirow[t]{2}{*}{$C_{\mathrm{Fp} 1}(\mathrm{FU})$} & $1877^{\mathrm{d}}$ & $1165^{\mathrm{a}}$ & $1255^{\mathrm{ab}}$ & $1265^{\mathrm{ab}}$ & $1427^{\mathrm{bc}}$ & $1157^{\mathrm{a}}$ & $1519^{\mathrm{c}}$ & $1892^{\mathrm{d}}$ \\
\hline & \pm 100 & \pm 79 & \pm 93 & \pm 24 & \pm 58 & \pm 113 & \pm 21 & \pm 31 \\
\hline \multirow[t]{2}{*}{$t_{\text {RMAXp1 }}(\min )$} & $0.17^{\mathrm{a}}$ & $0.11^{\mathrm{a}}$ & $0.24^{\mathrm{a}}$ & $0.13^{\mathrm{a}}$ & $0.11^{\mathrm{a}}$ & $0.32^{\mathrm{a}}$ & $0.62^{\mathrm{b}}$ & $0.24^{\mathrm{a}}$ \\
\hline & \pm 0.17 & \pm 0.04 & \pm 0.05 & \pm 0.06 & \pm 0.1 & \pm 0.08 & \pm 0.05 & \pm 0.05 \\
\hline \multirow{2}{*}{$\begin{array}{l}R_{\mathrm{MAXp} 1} \\
\left(\mathrm{FU} \cdot \mathrm{min}^{-1}\right)\end{array}$} & $3623^{\mathrm{ab}}$ & $2064^{\mathrm{a}}$ & $2444^{\mathrm{a}}$ & $2040^{\mathrm{a}}$ & $1681^{\mathrm{a}}$ & $1131^{\mathrm{a}}$ & $1079^{\mathrm{a}}$ & $6200^{\mathrm{b}}$ \\
\hline & \pm 2725 & \pm 996 & \pm 1006 & \pm 417 & \pm 417 & \pm 358 & \pm 96 & \pm 690 \\
\hline \multirow[t]{2}{*}{$t_{\mathrm{RMINp} 1}(\min )$} & $0.86^{\mathrm{ab}}$ & $0.99^{\mathrm{ab}}$ & $0.79^{\mathrm{a}}$ & $0.92^{\mathrm{ab}}$ & $1.16^{\mathrm{b}}$ & $1.16^{\mathrm{b}}$ & $1.53^{\mathrm{c}}$ & $0.77^{\mathrm{a}}$ \\
\hline & \pm 0.02 & \pm 0.23 & \pm 0.07 & \pm 0.05 & \pm 0.07 & \pm 0.23 & \pm 0.06 & \pm 0 \\
\hline \multirow[t]{2}{*}{$R_{\mathrm{MINp} 1}\left(\mathrm{FU} \cdot \mathrm{min}^{-1}\right)$} & $-762^{\mathrm{a}}$ & $-306^{\mathrm{b}}$ & $-897^{\mathrm{a}}$ & $-203^{\mathrm{b}}$ & $-36^{\mathrm{b}}$ & $-377^{\mathrm{b}}$ & $-38^{\mathrm{b}}$ & $-1033^{\mathrm{a}}$ \\
\hline & \pm 238 & \pm 151 & \pm 109 & \pm 54 & \pm 50 & \pm 154 & \pm 6 & \pm 36 \\
\hline \multirow[t]{2}{*}{$t_{\mathrm{CFMIN}}=W_{\mathrm{p} 1}(\mathrm{~min})$} & $2.84^{\mathrm{b}}$ & $2.69^{\mathrm{b}}$ & $4.34^{\mathrm{c}}$ & $1.57^{\mathrm{a}}$ & $1.41^{\mathrm{a}}$ & $5.83^{\mathrm{d}}$ & $1.93^{\mathrm{a}}$ & $2.89^{\mathrm{b}}$ \\
\hline & \pm 0.13 & \pm 0.48 & \pm 0.32 & \pm 0.05 & \pm 0.20 & \pm 0.09 & \pm 0.07 & \pm 0.04 \\
\hline \multirow[t]{2}{*}{$C_{\text {FMIN }}(\mathrm{FU})$} & $1115^{\mathrm{d}}$ & $904^{c}$ & $238^{\mathrm{a}}$ & $1159^{\mathrm{d}}$ & $1413^{\mathrm{e}}$ & $556^{\mathrm{b}}$ & $1504^{\mathrm{f}}$ & $883^{c}$ \\
\hline & \pm 11 & \pm 6 & \pm 53 & \pm 8 & \pm 44 & \pm 16 & \pm 19 & \pm 15 \\
\hline \multirow[t]{2}{*}{$t_{\mathrm{p} 2}(\min )$} & $6.80^{\mathrm{b}}$ & $8.08^{\mathrm{c}}$ & $13.2^{\mathrm{d}}$ & $4.64^{\mathrm{a}}$ & $7.42^{\mathrm{bc}}$ & $16.40^{\mathrm{e}}$ & $8.12^{\mathrm{c}}$ & $6.57^{\mathrm{b}}$ \\
\hline & \pm 0.2 & \pm 0.15 & \pm 0.97 & \pm 0.02 & \pm 0.1 & \pm 0.28 & \pm 0.35 & \pm 0.07 \\
\hline \multirow[t]{2}{*}{$C_{\mathrm{Fp} 2}(\mathrm{FU})$} & $1353^{\mathrm{d}}$ & $1349^{d}$ & $505^{\mathrm{a}}$ & $1363^{\mathrm{d}}$ & $2178^{\mathrm{f}}$ & $846^{\mathrm{b}}$ & $1760^{\mathrm{e}}$ & $1201^{\mathrm{c}}$ \\
\hline & \pm 10 & \pm 7 & \pm 66 & \pm 10 & \pm 9 & \pm 26 & \pm 22 & \pm 5 \\
\hline \multirow[t]{2}{*}{$t_{\mathrm{RMAXp} 2}(\min )$} & $4.23^{\mathrm{bc}}$ & $5.50^{\mathrm{d}}$ & $7.28^{\mathrm{e}}$ & $2.81^{\mathrm{a}}$ & $4.93^{\mathrm{cd}}$ & $10.69^{\mathrm{f}}$ & $3.52^{\mathrm{ab}}$ & $4.31^{\mathrm{bc}}$ \\
\hline & \pm 0.23 & \pm 0.32 & \pm 0.68 & \pm 0.02 & \pm 0.09 & \pm 0.35 & \pm 0.08 & \pm 0.05 \\
\hline \multirow{2}{*}{$\begin{array}{l}R_{\mathrm{MAXp} 2} \\
\left(\mathrm{FU} \cdot \mathrm{min}^{-1}\right)\end{array}$} & $101^{\mathrm{c}}$ & $152^{\mathrm{d}}$ & $47^{\mathrm{a}}$ & $97^{\mathrm{c}}$ & $212^{\mathrm{e}}$ & $42^{\mathrm{a}}$ & $75^{\mathrm{b}}$ & $142^{\mathrm{d}}$ \\
\hline & \pm 5 & \pm 11 & \pm 8 & \pm 7 & \pm 8 & \pm 2 & \pm 3 & \pm 5 \\
\hline & $9.27^{\mathrm{b}}$ & $10.67^{\mathrm{d}}$ & $20.00^{\mathrm{e}}$ & $6.46^{\mathrm{a}}$ & $9.48^{\mathrm{bc}}$ & $20.00^{\mathrm{e}}$ & $10.12^{\mathrm{cd}}$ & $9.43^{\mathrm{b}}$ \\
\hline \multirow{3}{*}{ 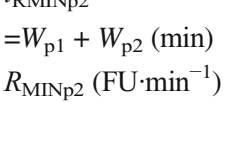 } & \pm 0.2 & 0.54 & \pm 0 & 0.02 & \pm 0.12 & \pm 0 & 0.27 & 0.15 \\
\hline & $-36^{\mathrm{d}}$ & $-47^{\mathrm{c}}$ & $-54^{\mathrm{c}}$ & $-88^{\mathrm{a}}$ & $-73^{\mathrm{b}}$ & $-34^{\mathrm{d}}$ & $-8^{\mathrm{e}}$ & $-71^{\mathrm{b}}$ \\
\hline & \pm 4 & \pm 1 & \pm 5 & \pm 1 & \pm 2 & \pm 0 & \pm 2 & \pm 2 \\
\hline \multirow[t]{2}{*}{$W_{\mathrm{p} 2}(\min )$} & $6.42^{\mathrm{b}}$ & $7.98^{\mathrm{c}}$ & $15.66^{\mathrm{e}}$ & $4.89^{\mathrm{a}}$ & $8.07^{\mathrm{c}}$ & $14.17^{\mathrm{d}}$ & $8.19^{\mathrm{c}}$ & $6.54^{\mathrm{b}}$ \\
\hline & \pm 0.07 & \pm 0.37 & \pm 0.30 & \pm 0.02 & \pm 0.18 & \pm 0.09 & \pm 0.27 & \pm 0.16 \\
\hline \multirow[t]{2}{*}{$W_{\mathrm{p} 2} / W_{\mathrm{p} 1}$} & $2.26^{\mathrm{a}}$ & $3.04^{\mathrm{abc}}$ & $3.62^{\mathrm{bc}}$ & $3.12^{\mathrm{abc}}$ & $5.81^{\mathrm{d}}$ & $2.43^{\mathrm{ab}}$ & $4.24^{\mathrm{c}}$ & $2.27^{\mathrm{a}}$ \\
\hline & \pm 0.08 & \pm 0.60 & \pm 0.32 & \pm 0.01 & \pm 0.97 & \pm 0.05 & \pm 0.21 & \pm 0.08 \\
\hline \multirow[t]{2}{*}{$S\left(10^{-3}\right)$} & $405^{\mathrm{c}}$ & $221^{\mathrm{b}}$ & $811^{\mathrm{e}}$ & $83^{\mathrm{a}}$ & $10^{\mathrm{a}}$ & $516^{\mathrm{d}}$ & $10^{\mathrm{a}}$ & $533^{\mathrm{d}}$ \\
\hline & \pm 36 & \pm 53 & \pm 28 & \pm 22 & \pm 15 & \pm 56 & \pm 2 & \pm 12 \\
\hline \multirow[t]{2}{*}{$H\left(10^{-3}\right)$} & $127^{\mathrm{a}}$ & $383^{\mathrm{d}}$ & $213^{\mathrm{bc}}$ & $161^{\mathrm{ab}}$ & $537^{\mathrm{e}}$ & $252^{\mathrm{c}}$ & $169^{\mathrm{ab}}$ & $168^{\mathrm{ab}}$ \\
\hline & \pm 4 & \pm 24 & \pm 10 & \pm 10 & \pm 49 & \pm 28 & \pm 3 & \pm 8 \\
\hline \multirow[t]{2}{*}{$t_{\mathrm{A}}(\min )$} & $6.30^{\mathrm{bc}}$ & $7.41^{\mathrm{c}}$ & $12.70^{\mathrm{d}}$ & $3.97^{\mathrm{a}}$ & $6.41^{\mathrm{bc}}$ & $15.62^{\mathrm{e}}$ & $6.80^{\mathrm{bc}}$ & $6.03^{\mathrm{b}}$ \\
\hline & \pm 0.35 & \pm 0.17 & \pm 0.96 & \pm 0.07 & \pm 0.23 & \pm 0.43 & \pm 0.32 & \pm 0.06 \\
\hline \multirow[t]{2}{*}{$A\left(\mathrm{FU} \cdot \mathrm{min}^{-1}\right)$} & $160^{\mathrm{e}}$ & $95^{\mathrm{cd}}$ & $102^{\mathrm{cd}}$ & $78^{\mathrm{bc}}$ & $122^{\mathrm{d}}$ & $57^{\mathrm{ab}}$ & $40^{\mathrm{a}}$ & $220^{\mathrm{f}}$ \\
\hline & \pm 25 & \pm 9 & \pm 12 & \pm 10 & \pm 5 & \pm 6 & \pm 2 & \pm 6 \\
\hline
\end{tabular}

Values in the same row followed by different superscript letters are significantly different from each other $(p<0.05)$ dehydration process. Furthermore, the analysis of the position of peak $\mathrm{p}_{2}$ (parameter $t_{\mathrm{p} 2}$ ) could provide additional information about the rate of hydration of the analysed fibre. The closer the position of this peak (shorter $t_{\mathrm{p} 2}$ ) to the onset of the mixing process, the greater the hydration rate of the fibre is.

At increasing supplementation with pineapple pomace fibre from 5 to $10 \%$ (Chareonthaikij et al. 2016), fenugreek 
fibre from 3 to $13 \%$ (Huang et al. 2016), and pulp carob fibre from 10 to $30 \%$ (Salinas et al. 2015), the standard farinograms obtained showed formation of increasingly higher second peaks, which suggested an increase in bread dough consistency induced by the fibre supplement. The investigations cited confirm that the presence of fibre in bread dough and its hydration properties determine the position and height of peak $\mathrm{p}_{2}$ on the difference farinogram. Furthermore, our present study (Table S1) indicates that the hydration rate is rather independent of the water absorption strength (no correlation between $t_{\mathrm{p} 2}$ and $\left.H\right)$. The CRB, CAR, and OAT fibres, characterised by identical water absorption strength $(H \sim 0.16-0.17)$, differed significantly in the hydration rate, with $t_{\mathrm{p} 2}$ values of $4.6,6.8$, and $8.1 \mathrm{~min}$, respectively.

In addition to changes in dough consistency, dehydration can modify the conformation of gluten proteins (Bock and Damodaran 2013; Nawrocka et al. 2015, 2016a, b; Pourfarzad et al. 2015). In turn, as reported by Noort et al. (2010) and Wang et al. (2004a, b), changes in dough consistency may primarily result from chemical interactions between the reactive components of fibre, e.g. between phenolic acids and gluten. Being natural antioxidants, the compounds can form complexes with proteins via hydrogen bonding between hydroxyl groups of phenols and the carbonyl group of the peptide residue of proteins. The aggregation of the protein chains results in increased firmness of the gluten network and dough consistency.

Similar to the $\mathrm{p}_{1}$ and $\mathrm{p}_{2}$ peak height, the degrees of weakening $(S)$ and strengthening $(H)$ were not correlated with each other. This implies the presence of two unrelated phenomena (processes) involved in dough softening and strengthening during the mixing stage. Therefore, full characterisation of the rheological activity of fibre should include determination of the balance between these two types of effects. Based on the $S / H$ ratio, the fibres were divided into two groups. The first group comprised the carrot, oat, cranberry, and cacao fibres which exhibited dominance of strengthening over weakening interactions $(S<H)$. The other group included chokeberry, carob, apple, and flax fibres which were characterised by dominance of weakening over strengthening effects $(S>H)$. Our previous studies (Miś et al. 2012) based on standard farinograph tests demonstrated formation of two peaks induced by addition of carob fibre and oat wholemeal. Despite the significant differences in the composition between the oat wholemeal and oat fibres and a substantially lower level of the carob fibre addition (1-5\%), the arrangement of the heights of these peaks for the oat wholemeal and carob fibre corresponded to that described in this study.

The duration $\left(t_{\mathrm{A}}\right)$ and intensity $(A)$ of the rheological activity were found to be useful criteria of rheological characterisation of the supplements (Table 2). Among these supplements, the cranberry fibre exhibited the shortest activity time (4 min), whereas the longest activity (nearly $16 \mathrm{~min}$ ) was found for the flax fibre. In turn, the oat fibre induced the least intense changes in the dough consistency (mean $40 \mathrm{FU} \mathrm{min}{ }^{-1}$ ), the rate of which was over fivefold lower than that induced by the carob fibre.

The correlation analysis did not show any significant correlation between WRC and any of the rheological parameters, suggesting its unsuitability in elucidation of the hydration phenomenon observed at the bread dough development stage (Table S1). In contrast, 11 significant correlations were found between the particle size distribution and the proposed rheological indices characterising the first peak shape. In case of the second peak, only one correlation was found indicating the decrease in the height of the second peak $\left(C_{\mathrm{Fp} 2}\right)$ with increase in the finest particles $(0.02-2 \mu \mathrm{m})$ content. This disproportion between the number of correlations, disadvantageous to the correlations between the fibre particle size and the shape of the second peak, may imply that the physical parameters of the particles cease to be relevant at the final bread dough development. The progressive disintegration of fibre particles during mixing leads to dough homogenisation as a mixture, where the boundaries between them and the gluten network disappear (Maeda et al. 2015). Hence, the primary processes influencing the $\mathrm{p}_{2}$ peak shape, especially water retention by the fibre and its interactions with gluten proteins, seem to have a typically chemical character.

To sum up, the analysis of the difference farinograms presented in this study reveals the complexity of processes influencing the fibre-supplemented bread dough development. The characteristic feature of these farinograms is the presence of the peaks, which allow to identify two stages in the dough development process: initial $\left(W_{\mathrm{p} 1}\right)$ and final $\left(W_{\mathrm{p} 2}\right)$. Undoubtedly, the course of the dough development stages reflects the interactions between the fibre supplement and flour components. However, detailed explanation of these interactions requires further investigations, in which the analysis of difference farinograms may be the key research tool.

\section{Conclusions}

The proposed method for analysis of farinograph curves facilitated identification and determination of the rheological effects induced by fibre supplements during the model dough mixing process. The difference curves determined with this method were characterised by the presence of two peaks $p_{1}$ and $\mathrm{p}_{2}$ exhibiting significant differences in the shape, height, and position on the mixing time axis, depending on the botanical origin of the fibre supplement. They divide the process of fibre-supplemented dough development into two stages. The initial stage $\left(W_{\mathrm{p} 1}\right)$ was characterised by highly dynamic changes in the dough consistency induced probably by hydration of fibre particles and inclusion thereof into the gluten network. It was shown that fibres exhibiting a longer time of 
$\mathrm{p}_{1}$ peak formation $\left(t_{\mathrm{p} 1}\right)$ had a beneficial effect and minimised the degree of gluten network weakening $(S)$ during the initial stage. The final stage of dough development $\left(W_{\mathrm{p} 2}\right)$ was, on average, two times longer. It consisted in molecular interactions between the fibres and the other dough components, primarily gluten. They could lead to partial dehydration and conformational changes in gluten proteins as well as formation of protein-fibre complexes, which was probably the major cause of the common phenomenon of strengthening the consistency of the fibre-supplemented dough. However, not in all the fibres analysed, the degree of strengthening $(H)$ was higher than the degree of weakening (S) observed at the initial dough development. Therefore, the complete characterisation of the mixing properties of fibre supplements should be based on an analysis of both peaks in difference farinograms.

The information provided by a difference farinogram can be useful also for characterisation of the hydration properties of bakery used fibres. Instead of the traditional WRC index, both the hydration rate and the water absorption strength by fibre should be determined, i.e. properties that actually determine the rheological behaviour of dough at the mixing stage. To achieve this aim, the interpretation of the position and height of $p_{1}$ and $p_{2}$ peaks on the difference farinogram proposed in this paper requires further experimental verification.

\section{Compliance with Ethical Standards}

Conflict of Interest The authors declare that they have no conflict of interest.

Open Access This article is distributed under the terms of the Creative Commons Attribution 4.0 International License (http:// creativecommons.org/licenses/by/4.0/), which permits unrestricted use, distribution, and reproduction in any medium, provided you give appropriate credit to the original author(s) and the source, provide a link to the Creative Commons license, and indicate if changes were made.

\section{References}

Ahmad, M. H., Nache, M., Waffenschmidt, S., \& Hitzmann, B. (2016). Characterization of farinographic kneading process for different types of wheat flours using fluorescence spectroscopy and chemometrics. Food Control, 66, 44-52.

Auffret, A., Ralet, M. C., Guillon, F., Barry, J. L., \& Thibault, J. F. (1994). Effect of grinding and experimental conditions on the measurement of hydration properties of dietary fibers. $L W T-$ Food Science and Technology, 27(2), 166-172.

Bchir, B., Rabetafika, H., Paquot, M., \& Blecker, C. (2014). Effect of pear, apple and date fibres from cooked fruit by-products on dough performance and bread quality. Food and Bioprocess Technology, 7(4), 1114-1127.

Bieganowski, A., Łagód, G., Ryżak, M., Montusiewicz, A., Chomczyńska, M., \& Sochan, A. (2012). Measurement of activated sludge particle diameters using laser diffraction method. Ecological Chemistry and Engineering S, 19, 597-608.
Bieganowski, A., Chojecki, T., Ryżak, M., Sochan, A., \& Lamorski, K. (2013). Methodological aspects of fractal dimension estimation on the basis of PSD. Vadose Zone Journal, 12(1). doi:10.2136/vzj2012.0064.

Bigne, F., Puppo, M. C., \& Ferrero, C. (2016). Rheological and microstructure characterization of composite dough with wheat and mesquite (Prosopis spp) flours. International Journal of Food Properties, 19(2), 243-256.

Bock, J. E., \& Damodaran, S. (2013). Bran-induced changes in water structure and gluten conformation in model gluten dough studied by Fourier transform infrared spectroscopy. Food Hydrocolloids, 31(2), 146-155.

Chareonthaikij, P., Uan-On, T., \& Prinyawiwatkul, W. (2016). Effects of pineapple pomace fibre on physicochemical properties of composite flour and dough, and consumer acceptance of fibre-enriched wheat bread. International Journal of Food Science and Technology, 51(5), 1120-1129.

Hammed, A. M., Ozsisli, B., Ohm, J. B., \& Simsek, S. (2015). Relationship between solvent retention capacity and protein molecular weight distribution, quality characteristics, and breadmaking functionality of hard red spring wheat flour. Cereal Chemistry, 92(5), 466-474.

Han, H. M., \& Koh, B. K. (2011). Effect of phenolic acids on the rheological properties and proteins of hard wheat flour dough and bread. Journal of the Science of Food and Agriculture, 91(13), 2495-2499.

Huang, G., Guo, Q., Wang, C., \& Cui, S. W. (2016). Fenugreek fibre in bread: effects on dough development and bread quality. LWT-Food Science and Technology, 71, 274-280.

Jacobs, P. J., Hemdane, S., Dornez, E., Delcour, J. A., \& Courtin, C. M. (2015). Study of hydration properties of wheat bran as a function of particle size. Food Chemistry, 179, 296-304.

Krishnaiya, R., Kasar, C., \& Gupta, S. (2016). Influence of water chestnut (Trapa natans) on chemical, rheological, sensory and nutritional characteristics of muffins. Journal of Food Measurement and Characterization, 10(2), 210-219.

Lefebvre, J., \& Mahmoudi, N. (2007). The pattern of the linear viscoelastic behaviour of wheat flour dough as delineated from the effects of water content and high molecular weight glutenin subunits composition. Journal of Cereal Science, 45, 49-58.

Letang, C., Piau, M., \& Verdier, C. (1999). Characterization of wheat flour-water doughs. part I: rheometry and microstructure. Journal of Food Engineering, 41, 121-132.

Ma, M., \& Mu, T. (2016). Effects of extraction methods and particle size distribution on the structural, physicochemical, and functional properties of dietary fiber from deoiled cumin. Food Chemistry, 194, 237-246.

Maeda, T., Kokawa, M., Nango, N., Miura, M., Araki, T., Yamada, M., Takeya, K., \& Sagara, Y. (2015). Development of a quantification method of the gluten matrix in bread dough by fluorescence microscopy and image analysis. Food and Bioprocess Technology, 8(6), 1349-1354.

Majzoobi, M., Pashangeh, S., Aminlari, L., \& Farahnaky, A. (2014). Modeling the effects of the quantity and particle size of wheat bran on some properties of bread dough using response surface methodology. International Journal of Food Engineering, 10(3), 511-519.

Massiot, P., \& Renard, C. M. G. C. (1997). Composition, physicochemical properties and enzymatic degradation of fibres prepared from different tissues of apple. Food Science and TechnologyLebenmittel-Wissenschaft, 30(8), 800-806.

Mert, B., Tekin, A., Demirkesen, I., \& Kocak, G. (2014). Production of microfluidized wheat bran fibers and evaluation as an ingredient in reduced flour bakery product. Food and Bioprocess Technology, 7(10), 2889-2901.

Migliori, M., \& Correra, S. (2013). Modelling of dough formation process and structure evolution during farinograph test. International Journal of Food Science and Technology, 48(1), 121-127. 
Miś A., \& Nawrocka A. (2015). Method for determining rheological properties of fibre supplements of bread. Polish patent application number: P.415134 (PL), filing date: 2015-12-04.

Miś, A., Grundas, S., Dziki, D., \& Laskowski, J. (2012). Use of farinograph measurements for predicting extensograph traits of bread dough enriched with carob fibre and oat wholemeal. Journal of Food Engineering, 108, 1-12.

Nawrocka, A., Szymańska-Chargot, M., Miś, A., Ptaszyńska, A., Kowalski, R., Waśko, P., \& Gruszecki, W. (2015). Influence of dietary fibre on gluten proteins structure - a study on model flour with application of FT-Raman spectroscopy. Journal of Raman Spectroscopy, 46(3), 309-316.

Nawrocka, A., Mis, A., \& Szymańska-Chargot, M. (2016a). Characteristics of relationships between structure of gluten proteins and dough rheology - influence of dietary fibres studied by FTRaman spectroscopy. Food Biophysics, 11(1), 81-90.

Nawrocka, A., Szymańska-Chargot, M., Miś, A., Kowalski, R., \& Gruszecki, W. (2016b). Raman studies of gluten proteins aggregation induced by dietary fibres. Food Chemistry, 194(2016), 86-94.

Nicolae, A., Radu, G. L., \& Belc, N. (2016). Effect of sodium carboxymethyl cellulose on gluten-free dough rheology. Journal of Food Engineering, 168, 16-19.

Noort, M. W. J., van Haaster, D., Hemery, Y., Schols, H. A., \& Hamer, R. J. (2010). The effect of particle size of wheat bran fractions on bread quality - evidence for fibre-protein interactions. Journal of Cereal Science, 52(1), 59-64.

Pourfarzad, A., Najafi, M. B. H., Khodaparast, M. H. H., \& Khayyat, M. H. (2015). Serish inulin and wheat biopolymers interactions in model systems as a basis for understanding the impact of inulin on bread properties: a FTIR investigation. Journal of Food Science and Technology-Mysore, 52(12), 7964-7973.

Quayson, E. T., Atwell, W., Morris, C. F., \& Marti, A. (2016). Empirical rheology and pasting properties of soft-textured durum wheat (Triticum turgidum ssp durum) and hard-textured common wheat (T. aestivum). Journal of Cereal Science, 69, 252-258.
Raghavendra, S. N., Rastogi, N. K., Raghavarao, K. S. M. S., \& Tharanathan, R. N. (2004). Dietary fiber from coconut residue: effects of different treatments and particle size on the hydration properties. European Food Research and Technology, 218(6), 563-567.

Rosa, N. N., Barron, C., Gaiani, C., Dufour, C., \& Micard, V. (2013). Ultra-fine grinding increases the antioxidant capacity of wheat bran. Journal of Cereal Science, 57(1), 84-90.

Rosell, C. M., Santos, E., \& Collar, C. (2006). Mixing properties of fibreenriched wheat bread doughs: a response surface methodology study. European Food Research and Technology, 223, 333-340.

Roth, M., Doring, C., Jekle, M., \& Becker, T. (2016). Mechanisms behind distiller's grains impact on wheat dough and bread quality. Food and Bioprocess Technology, 9(2), 274-284.

Salinas, M. V., Carbas, B., Brites, C., \& Puppo, M. C. (2015). Influence of different carob fruit flours (Ceratonia siliqua L.) on wheat dough performance and bread quality. Food and Bioprocess Technology, $8(7), 1561-1570$.

Stojceska, V., \& Butler, F. (2008). Digitization of farinogram plots and estimation of mixing stability. Journal of Cereal Science, 48, 729733.

Teng, Y., Liu, C., Bai, J., \& Liang, J. (2015). Mixing, tensile and pasting properties of wheat flour mixed with raw and enzyme treated rice bran. Journal of Food Science and Technology-Mysore, 52(5), 3014-3021.

Wang, M. W., van Vliet, T., \& Hamer, R. J. (2004a). Evidence that pentosans and xylanase affect the re-agglomeration of the gluten network. Journal of Cereal Science, 39, 341-349.

Wang, M. W., van Vliet, T., \& Hamer, R. J. (2004b). How gluten properties are affected by pentosans. Journal of Cereal Science, 39, 395402.

Zhang, D. C., \& Moore, W. R. (1999). Wheat bran particle size effects on bread baking performance and quality. Journal of the Science of Food and Agriculture, 79(6), 805-809. 